\title{
Organic Redox-Flow Batteries Using Hair Dyes and Pharmaceuticals
}

\author{
Dominique Rosenberg ${ }^{*}$, Svenja Pansegrau, Mirco Wachholz, Anja Köppen, Maike Busker, Walter Jansen \\ Chemistry and Chemistry Education, Institute of Mathematic, Scientific and Technical Literacy, \\ Europa-Universität Flensburg, Flensburg, Germany \\ *Corresponding author: dominique.rosenberg@uni-flensburg.de
}

\begin{abstract}
In the last few years the number of renewable energy sources (e.g. wind or solar energy) increased drastically. The availability of solar energy depends on the amount of daily sun light and the availability of electric power from wind turbines is linked to the available wind offered by nature. The increase of power from renewable energy sources has to be combined with innovative energy storage systems. Solar, wind and other renewable energy sources are intermittent energy sources. Consequently, with more renewable energy sources the amount of intermittent energy increases, too. Due to this, there is a need for more and more flexible and efficient energy storage systems with high capacities to guarantee the stability of the electric grid. Such energy storage systems, which are discussed right at the moment, are so called flow batteries. This article presents an experimental set-up that demonstrates the functionality of Redox-Flow-Batteries to students in chemistry lessons. Such efficient organic Redox-Flow-Batteries can use hair dyes like Phenylenediamine and pharmaceuticals such as Paracetamol. The decomposition product of Paracetamol, p-Aminophenol proved to be a particular suitable candidate, which is shown via cyclic voltammetry.
\end{abstract}

Keywords: organic redox-flow-battery, phenylenediamine, paracetamol, p-Aminophenol

Cite This Article: Dominique Rosenberg, Svenja Pansegrau, Mirco Wachholz, Anja Köppen, Maike Busker, and Walter Jansen, "Organic Redox-Flow Batteries Using Hair Dyes and Pharmaceuticals." World Journal of Chemical Education, vol. 6, no. 1 (2018): 63-71. doi: 10.12691/wjce-6-1-10.

\section{Introduction}

The storage of wind and solar energy is an important task at hand. For this matter Lithium-ion batteries and so called Redox-Flow-Batteries are currently being discussed $[1,2]$. Redox-Flow-Batteries are galvanic cells, in which electrochemical active substances in aqueous solution circulate between carbon electrodes. If there is an excess of electrical energy present, these batteries can be charged and if necessary discharged thus releasing the stored energy. There exist sophisticated systems in which vanadium compounds in the oxidation state (II) or (V) are implemented. Just as inorganic systems, organic redox systems can be used for Redox-Flow-Batteries. This was impressively demonstrated by Aziz et al. [3,4] and Narayanan et al. [5], who used Anthraquinone disulfonic acid and Bromine or Benzoquinone, respectively, to successfully operate a Redox-Flow-Battery.

In our previous communications $[6,7,8]$ we showed that Alizarin, Gallic acid and Pyrogallol can be used as anodic material for organic batteries. Green tea and the flavoring substance Vanillin can be likewise electrochemically oxidized [9]. As cathodic materials the use of o- and p-Benzoquinone in an iron(III) sulfate solution or the carbon/oxygen-electrode described by Oetken [14] have been already discussed. Organic batteries seem to be an eligible object in chemistry education to show that even organic materials can be electrochemically reduced or oxidized. Moreover can everyday life materials like green tea, be implemented in striking experiments [8], because of its high content of Polyphenols like Epigallocatechin gallate, e.g. The term "antioxidant” can be clarified in this context, too.

A prerequisite for using a Redox-Flow-Battery is the complete rechargeability of the Redox-System (anodic and cathodic sides). This can be easily achieved with inorganic materials but not as easily with organic materials. In order to evaluate the rechargeability and stability of the redox systems cyclic voltammetry is used. Following a short explanation of cyclic voltammetry, the experiments with Phenylenediamine and Paracetamol are discussed. Especially the Redox-Flow-Battery with Paracetamol shows very promising results for future uses.

\section{Cyclic Voltammetry}

The electrochemical measurement method Cyclic Voltammetry (CV) records the resulting current of an applied triangular voltage using diluted solutions (1-2 $\mathrm{mMol} / \mathrm{L}$ ) of the examined substance. Due to the triangular voltage the substance is oxidized and afterwards reduced. The responding current is recorded. The inversion of the potential is conducted with the same speed. The potential of the working electrode is determined by a reference electrode, normally a silver/silverchloride electrode. The 
used working electrode was a "glassy carbon electrode", whose carbon surface was equal to the surface of the carbon foil. A platinum electrode was used as a counter electrode in our experiments.

If a redox reaction sets in at a defined potential according to $\mathrm{A}+\mathrm{e}-\rightarrow \mathrm{B}$ at an electrode, the current can be measured. Increasing the potential leads to an increase of the current resulting in a maximum and successive decrease of the current. This behavior is the result of the low concentration of the oxidisable substance near to the electrode surface and the limited transportation due to a diffusion controlled measurement. The diffusion coefficients in aqueous solution are around $\mathrm{D}=1-310^{-5} \mathrm{~cm}^{2} / \mathrm{s}$ and lead to a characteristic peak. Instead of the starting substance its oxidized form is near to the surface of the electrode. During the back scan the electrode potential is decreased until the reduction potential of the oxidized form is reached thus leading to an answering current, a new peak, but with the reversed direction. The anodic peak $\left(E p_{a}\right)$ during the oxidation and the cathodic peak $\left(\mathrm{Ep}_{\mathrm{k}}\right)$ during reduction differ in the voltage around $\Delta \mathrm{Ep}=55-60 \mathrm{mV}$. The resulting current is ideally the same for $\mathrm{ip}_{\mathrm{a}}$ und $\mathrm{ip}_{\mathrm{k}}$. They are determined by the distance of the peakmaxima and the baseline (cf. Figure 1).

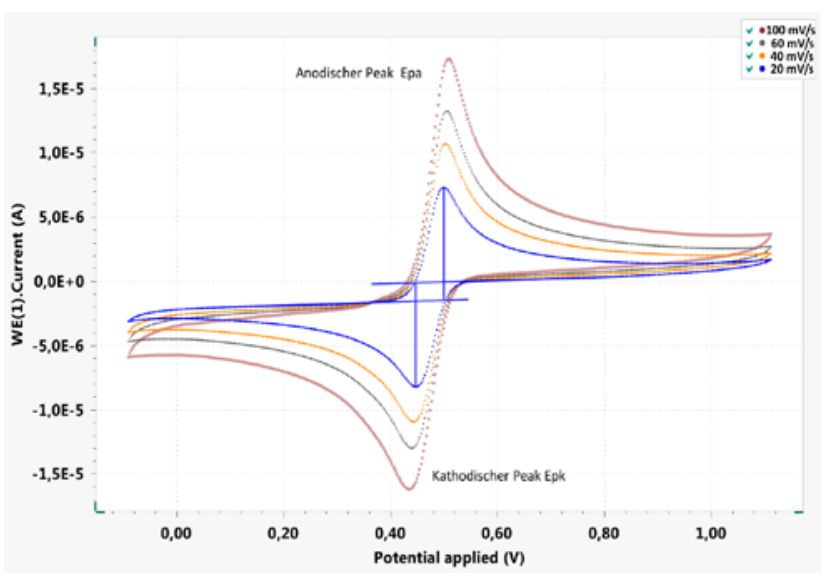

Figure 1. Cyclic voltammogram of $\rho$-Benzoquinone against $\mathrm{Ag} / \mathrm{AgCl}$

We conducted three scans with the same speed $\mathrm{dE} / \mathrm{dt}$ and used the data of the third scan for the evaluation. The speed of the following scans was increased from $20 \mathrm{mV} / \mathrm{s}$ to $40 \mathrm{mV} / \mathrm{s}$, to $60 \mathrm{mV} / \mathrm{s}$ and finally to $100 \mathrm{mV} / \mathrm{s}$. Due to the increase of the scan speed, the electrochemical processes have to take place in a shorter amount of time thus leading to a heightening of the voltage peaks of $\sqrt{\frac{d E}{d t}}$. The peaks will shift to either higher potentials (forward scan) or lower potentials (backward scan) resulting in a higher $\Delta \mathrm{Ep}$. Observing uninhibited or slightly inhibited systems, this effect should be minor, too. Even at higher scan rates the value of ip should equal $\mathrm{ip}_{\mathrm{k}}$. The half-wave potential for an uninhibited charge transfer

$$
E_{\frac{1}{2}}=\frac{1}{2}\left(E p_{a}-E p_{k}\right)
$$

and equals the resting potential calculated by the Nernst equation. One can discern three types of reactions: reversible, quasi-reversible and irreversible.
For reversible reactions, there is an uninhibited charge transfer between electrode and molecules and vice versa. The cyclic voltammogram shows a $\Delta \mathrm{Ep}=55-65 \mathrm{mV}$ for one electron transfer, around $30 \mathrm{mV}$ for a transfer of two electrons and $\mathrm{ip}_{\mathrm{a}}=\mathrm{ip}_{\mathrm{k}}$. The peak heights increase by $\sqrt{\frac{d E}{d t}}$ whilst the scan speed is increased by $\mathrm{dE} / \mathrm{dt} . \Delta \mathrm{Ep}$ shows no noteworthy change. For quasi-reversible reactions there is a slight inhibition of the charge transfer and $\Delta \mathrm{Ep}$ is between $65 \mathrm{mV}$ and $170 \mathrm{mV}$. ipa still equals ipk. The difference between the peaks $(\Delta E \mathrm{E})$ increases clearly while raising the scan speed but the heights of the peaks should still grow by the factor $\sqrt{\frac{d E}{d t}}$. A shift of $30 \mathrm{mV}$ for $\Delta \mathrm{Ep}$ while increasing the scan rate by a factor of 10 stands for a charge transfer coefficient $\alpha=0,5$, a quasi-reversible reaction according to [10]. The charge transfer for irreversible reactions is strongly inhibited yielding values of $\Delta \mathrm{Ep}>170 \mathrm{mV}$. Furthermore, it is possible, that there is no distinct peak present in the $\mathrm{CV}$, meaning that $\Delta$ Ep cannot be determined.

In the cyclic voltammogram consecutive reactions like further oxidation- and reduction reactions can be recognized. Organic redox systems, which can be used in school $[6,7,8,9]$, only $\rho$-Benzoquinone and Anthraquinone-disulfonic acid prove to be rechargeable in potentiometric measurements and have been already described by Aziz et al. and Narayanan et al. The system iron(III)/iron(II) (ammonium iron(II) sulfate in acidic medium) shows quasi-reversible behavior. Especially systems which can be derived by everyday life materials (green tea, cacao, for e.g.) proved not to be rechargeable.

Herinafter two substances will be presented, $\rho$-Phenylenediamine in hair dyes and $\rho$-Aminophenol in developer solution, which show potential use in Redox-Flow batteries due to their results in cyclic voltammetry. The third example, the Paracetamol battery, represents a system, which changes with time from a nonrechargeable to a rechargeable battery.

\section{Experimental Section}

The template is used to format your paper and style the text. All margins, column widths, line spaces, and text fonts are prescribed; please do not alter them. Your paper is one part of the entire proceedings, not an independent document. Please do not revise any of the current designations.

\subsection{Experiments with $\rho$-Phenylenediamine}

$\rho$-Phenylenediamine (cf. Figure 2) is a diamine derivative of benzene. Its solubility in water at $25{ }^{\circ} \mathrm{C}$ is moderate $(47 \mathrm{~g} / \mathrm{L})$. It exhibits increased solubility in sodium hydroxide solution, thus the possibility to use $\rho$ Phenylenediamine in basic solution as anodic material. $\rho$ Phenylenediamine is produced in large amounts as an intermediate of the production of aromatic polyamides and in the plastics industry. It is used in everyday life in hair dyes and cosmetics. It is worth mentioning, that the use of $\rho$-Phenylenediamine can cause allergic reactions. 
<smiles>Nc1ccc(N)cc1</smiles>

Figure 2. $\rho$-Phenylenediamine

\subsubsection{Experiment 1:}

\section{p-Phenylenediamine/oxygen-battery}

Used Equipment: beaker glasses (600 mL and $100 \mathrm{~mL}$ ), earthenware pot, sealed with a fitting rubber plug at the, carbon foil (approx. $3 \mathrm{~cm} \times 4 \mathrm{~cm}$, carbon/oxygen electrode (according to Oetken et. al [15]), powerful electric motor, multimeter, wires, crocodile clips, silver/silverchlorideelectrode, stand material (if necessary), magnetic stirrer, low voltage power supply (resources cf. [6,7])

Chemicals: $\rho$-Phenylenediamine (Sigma Aldrich, Product Number P6001, 100 g, 56,40 €), sodium hydroxide $\mathrm{c}(\mathrm{NaOH})=1 \mathrm{~mol} / \mathrm{L}$, sulfuric acid $\mathrm{c}(\mathrm{H} 2 \mathrm{SO} 4)=1 \mathrm{~mol} / \mathrm{L}$, potassium chloride solution $\mathrm{c}(\mathrm{KCl})=1 \mathrm{~mol} / \mathrm{L}$, sodium persulfate (resources cf. [6, 7]).

Procedure: $2,5 \mathrm{~g}$ of $\rho$-phenylenediamine are solved in $150 \mathrm{~mL}$ sodium hydroxide solution $(\mathrm{c}=1 \mathrm{~mol} / \mathrm{L})$ in the large beaker glass where the carbon foil is added to, too. The earthenware pot is loaded with $100 \mathrm{~mL}$ sulfuric acid (c $=1 \mathrm{~mol} / \mathrm{L}$ ) and $5-10 \mathrm{~g}$ sodium persulfate. The earthenware pot is then put into the large beaker glass and the carbon/oxygen electrode [14] is put into place. This electrode is suitable for absorbing oxygen in its small pores thus enabling an electrochemical reaction. Oxygen and hydrogenperoxide are directly provided at the electrode due to the addition of sodium persulfate and the formation of its decomposition products in aqueous solutions. In contrast to its oxidation potential sodium persulfate does not affect the electrode potential [15].

The silver/silverchloride-electrode is installed in a small beaker glass with potassium chloride solution and a ion connection is established via a filter paper soaked in a potassium chloride solution. The electrodes are connected with wires as it is shown in figure 3. Initially the electric motor and amperemeter are not included in the electric circuit in order to measure the resting potential and voltage of the battery (without electrical load). Afterwards the electric motor and amperemeter are included in the circuit (cf. Figure 3) and the voltage and current are measured each minute over a period of 30 minutes and noted. The electric motor is removed from the circuit and the voltage of the battery is measured again. After discharging the battery it is loaded at $3 \mathrm{~V}$ for 15 minutes. The voltage of the battery (without electrical load) is measured again as well as the current and voltage under stress.

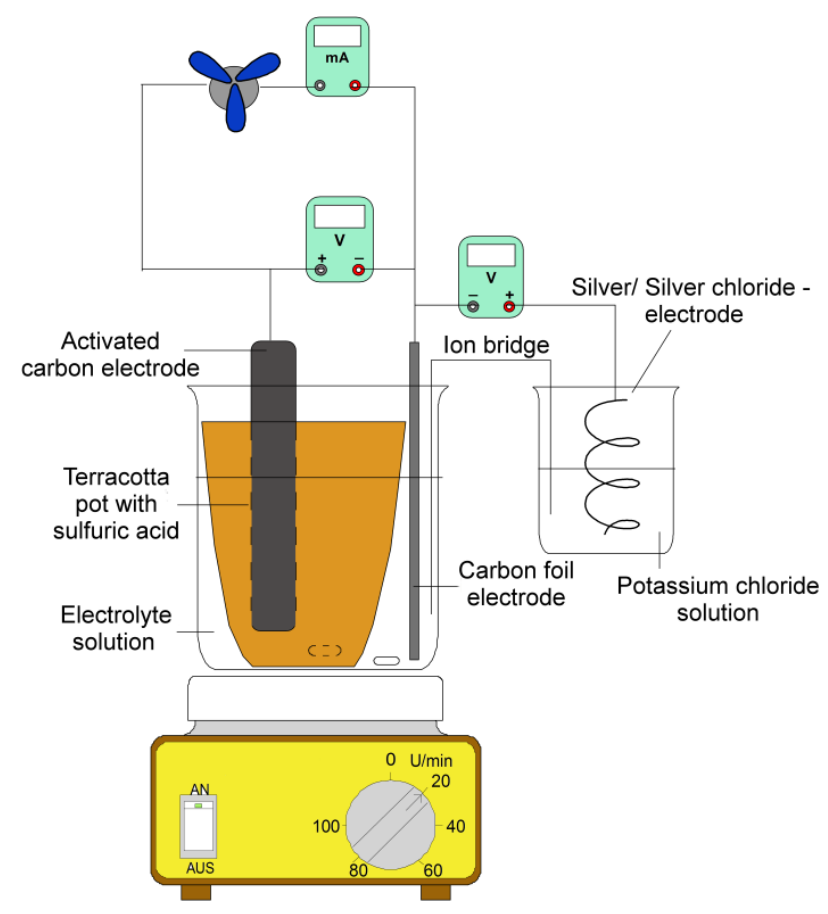

Figure 3. Experimental setup for experiment 1: the p-Phenylenediamine/oxygen - battery

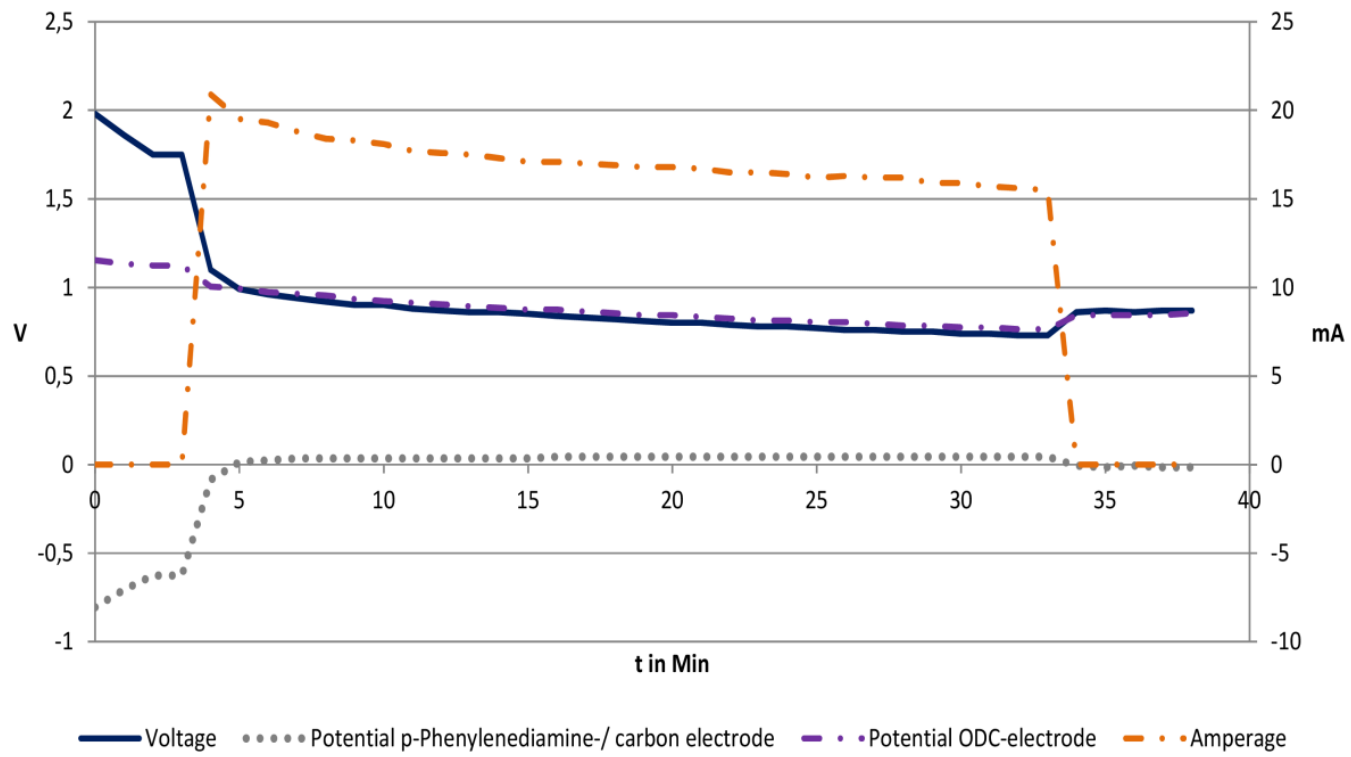

Figure 4. Measured voltage, current and potential of the p-Phenylenediamine/Oxygen-battery 


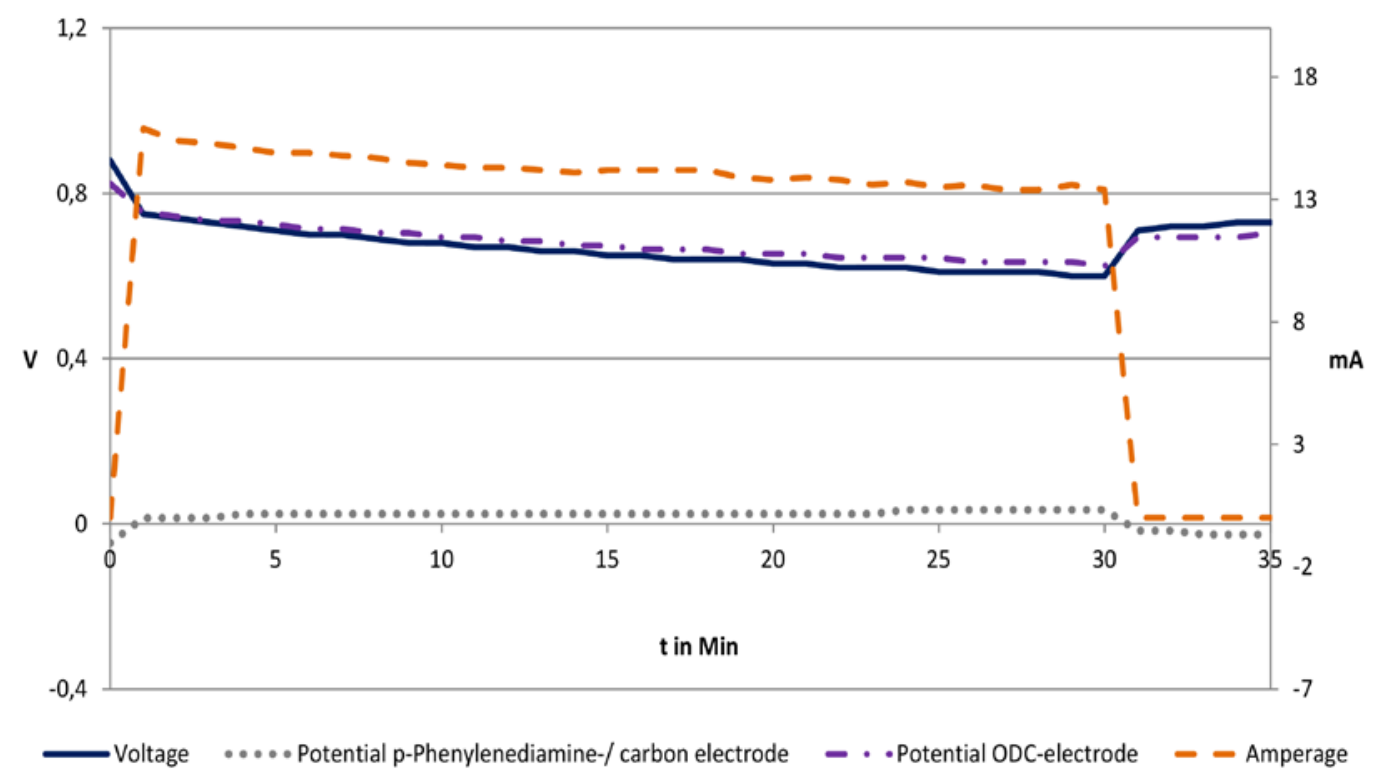

Figure 5. Measured voltage, current and potential of the p-Phenylenediamine/Oxygen-battery after charging

Results and discussion: At the beginning of our experiment, the voltage of the battery (without electrical load) was measured at almost $0,90 \mathrm{~V}$, and the resting potential of $\rho$-Phenylenediamine/graphite electrode at $-0,05 \mathrm{~V}$. After integration of the electric motor and the amperemeter in the circuit the propeller was rotating very fast. The electric motor consumed a current of $16 \mathrm{~mA}$. The voltage dropped from $0,76 \mathrm{~V}$ to $0,60 \mathrm{~V}$ in the course of 30 minutes. The resting potential of the $\rho$-Phenylenediamine/graphite electrode increased to $+0,03$ V. Figure 4 shows the basic measurements. After charging for 15 minutes, the powerful electric motor could be operated at throughout improved measurements (cf. Figure 5).

After recharging, the cell was able to supply three powerful electric motors with power. The current consumption dropped slightly from $64 \mathrm{~mA}$ to 60 . The voltage was stable at $0,60 \mathrm{~V}$ and the potential of the $\rho$-Phenylenediamine/graphite electrode at $+0,17 \mathrm{~V}$. The cell could be operated after numerous recharging cycles with the same results.

The discharge leads to the oxidation of p-Phenylenediamine and formation of p-Benzo-quinone diimine and the release of two electrons at the anode (cf. Figure 6). Oxygen is simultaneously reduced at the cathode (cf. Figure 7).<smiles>Nc1ccc(N)cc1</smiles><smiles>Nc1cc(N)cc(C=O)c1</smiles><smiles>N=C1C=CC(=N)C=C1</smiles>

Figure 6. Oxidation of p-Phenylenediamine
(1) $\mathrm{O}_{2}+4 \mathrm{H}^{+}($aq $)+4 \mathrm{e} \rightleftharpoons 2 \mathrm{H}_{2} \mathrm{O}$

(2) $\mathrm{Fe}^{3+}+\mathrm{e}=\mathrm{Fe}^{2+}$

(3)

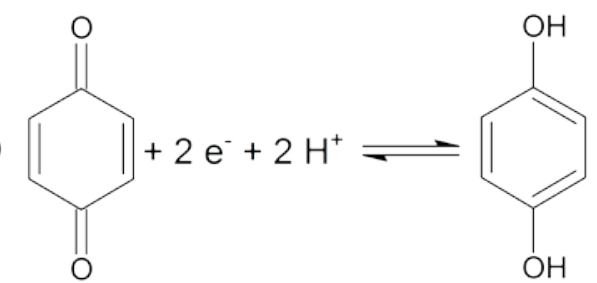

Figure 7. Reduction of oxygen (1), iron(III)sulfate (2) und p-benzoquinone (3)

The results demonstrate impressively, that the p-Phenylenediamine/Oxygen-Battery represents a rechargeable electrochemical cell. This conclusion is furthermore confirmed via the cyclovoltammogramm (cf. Figure 8). It shows a quasi-reversible behavior of p-Phenylenediamine in alkaline solution, with an increased inhibition of the reduction reaction.

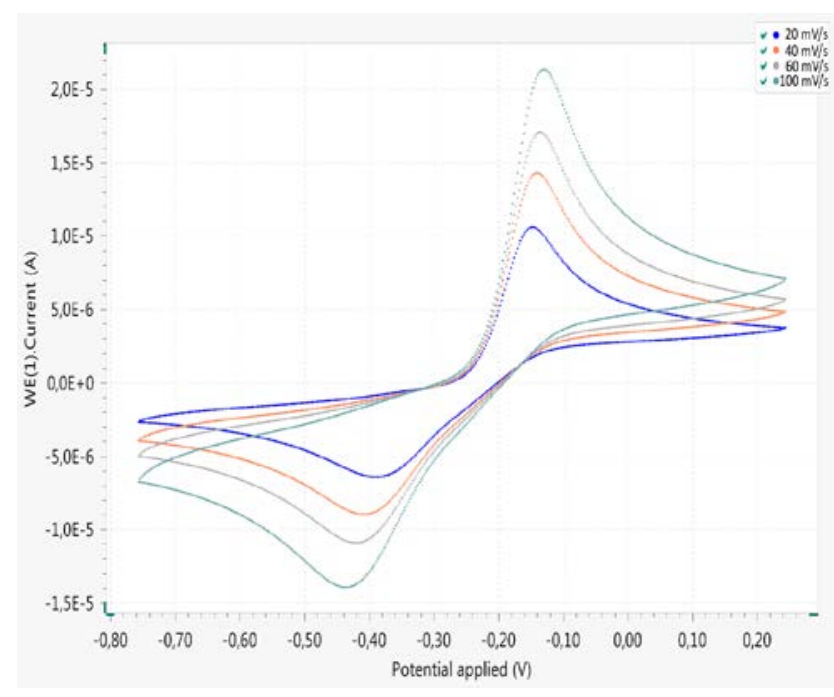

Figure 8. Cyclovoltammogramm of $\rho$-Phenylenediamine against $\mathrm{Ag} / \mathrm{AgCl}$ 


\subsubsection{Experiment 2:} $\rho$-Phenylenediamine/iron(III)-Sulfate-battery

In order to facilitate the use of a flow cell, the oxygen cathode was substituted by an aqueous iron(III)-sulfate solution as the cathodic material.

Used Equipment: cf. experiment 1. Instead of the graphite/oxygen-electrode an extra carbon foil is needed.

Chemicals: cf. experiment 1. Instead of sodium persulfate iron(III)-sulfate nonahydrate and iron(II)-sulfate hexahydrate are used.

Procedure: The procedure is analog to experiment 1 . $270 \mathrm{~g}$ iron(III)-sulfate nonahydrate and $5 \mathrm{~g}$ iron(II)-sulfate hexahydrate are dissolved in $300 \mathrm{~mL}$ water and $100 \mathrm{~mL}$ sulfuric acid are added. The earthenware pot is loaded with $100 \mathrm{~mL}$ of this solution and a carbon foil is put into place. First of all the voltage of the battery (without electrical load) and the potential of the p-Phenylinediamine/graphite electrode are measured. Afterwards the electric motor and amperemeter are connected to the circuit and the current and voltage are determined over a period of 30 minutes. The voltage of the battery (without electrical load) is measured again.

Results and interpretation: The voltage of the battery (without electrical load) was measured to be at $0,78 \mathrm{~V}$ during our experiment and the resting potential of the p-Phenylinediamine/graphite electrode at $0,01 \mathrm{~V}$. After implementing the electric motor and amperemeter into the circuit, the average current intake was 13,8 mA. The voltage was constant during the 30 minute long experiment at 0,57 $\mathrm{V}$. The potential of the $\mathrm{p}$-Phenylinediamine/graphite electrode was $0,0 \mathrm{~V}$. The discharge leads to the oxidation of p-Phenylenediamine and formation of p-Benzoquinone diimine and the release of two electrons at the anode (cf. Figure 6). Iron(III) ions are likewise reduced at the cathode (cf. Figure 7).

The recharging process after operating the battery for 30 minutes showed no significant change. This leads to the conclusion, that the $\rho$-Phenylenediamine/iron(III)-sulfate cell represents a readily rechargeable system and thus a suitable system for Redox-Flow-Batteries. This conclusion is further confirmed by the cyclicvoltammogram.

p-Benzoquinone is a suitable cathode material with a potential of $+0,8 \mathrm{~V}$ against carbon foils as was shown by Aziz et al. [3,4]. $\rho$-Benzoquinone-disulfonic acid was used because of its increased solubility compared to the moderate solubility of $\rho$-Benzoquinone in water. Unfortunately $\rho$-Benzoquinone disulfonic acid is not commercially available. In order to increase the solubility $10 \mathrm{~g}$ of $\rho$-Benzoquinone are solved in a mixture of 100 $\mathrm{mL}$ glacial acetic acid and $100 \mathrm{~mL}$ sulfuric acid $\left(\mathrm{c}\left(\mathrm{H}_{2} \mathrm{SO}_{4}\right)\right.$ $=1 \mathrm{~mol} / \mathrm{L})$. The use of glacial acetic acid makes it possible to solve $\rho$-Benzoquinone without problems and thereby, as shown by the experimental data, leading to a pure organic battery. Not only the weak but also the powerful electric motor can be operated over a long period of time without problems.

\subsection{Experiments with Paracetamol and p-Aminophenol}

Paracetamol (cf. Figure 9) is a derivative of p-Aminophenol, which is used to a great extent as a medication against pain and fever [16]. Although being known since 1878, its application as a widely used medication started during the sixties of the 20th century. Paracetamol advanced to an almost essential medication in modern days. Even though the metabolized Paracetamol can yield toxic compounds, usually it is deactivated in the liver through sulfate ions or glucuronic acid and excreted through the kidneys. N-acetyl-p-benzoquinone imine (cf. Figure 9) is a toxic possible byproduct of the oxidization of Paracetamol. It is metabolized through enzymes but it is recommended not to overdose the use of Paracetamol [17].

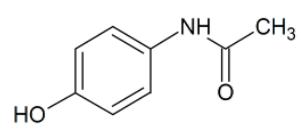

[1]<smiles>Nc1ccc(O)cc1</smiles>

[2]<smiles>CC(=O)N=C1C=CC(=O)C=C1</smiles>

[3]
Figure 9. [1] Paracetamol, [2] p-Aminophenol and [3], N-acetyl-pbenzoquinone imine

\subsubsection{Experiment 3: Paracetamol Battery with the Carbon/Oxygen Electrode}

Used Equipment: beaker glasses (600 mL and $100 \mathrm{~mL}$ ), earthenware pot, sealed with a fitting rubber plug at the, carbon foil (approx. $3 \mathrm{~cm} \times 4 \mathrm{~cm}$, carbon/oxygen electrode (Oetken et. al [15]), powerful electric motor, multimeter, wires, crocodile clips, silver/silverchloride-electrode, stand material (if necessary), magnetic stirrer

Chemicals: sodium hydroxide $\mathrm{c}(\mathrm{NaOH})=1 \mathrm{~mol} / \mathrm{L}$, sulfuric acid $\mathrm{c}\left(\mathrm{H}_{2} \mathrm{SO}_{4}\right)=1 \mathrm{~mol} / \mathrm{L}$, potassium chloride solution $\mathrm{c}(\mathrm{KCl})=1 \mathrm{~mol} / \mathrm{L}$, sodium persulfate, Paracetamol tablets (500 mg/tablet).

Procedure: 8 grinded Paracetamol tablets are solved in $150 \mathrm{~mL}$ sodium hydroxide solution, transferred into the large beaker glass and the carbon foil is added. The earthenware pot is filled with $100 \mathrm{~mL}$ sulfuric acid, 5-10 $\mathrm{g}$ of sodium persulfate are added and the carbon/oxygen electrode according to Oetken is put into place. The earthenware pot is then put into the large beaker glass and the electrodes and the multimeter are connected as it is shown in Figure 3. Initially the electric motor and amperemeter are not included in the electric circuit in order to measure the potential of the carbon foil in the Paracetamol solution with the silver/silverchloride electrode.

Results and interpretation: The voltage of the battery (without electrical load) increased to $1,08 \mathrm{~V}$ in a in the course of 10 minutes. The resting potential of the carbon foil in the Paracetamol solution was at $+0,03 \mathrm{~V}$. After integration of the electric motor in the circuit the propeller was rotating very fast. The electric motor consumed a current of approximately $20 \mathrm{~mA}$. The voltage dropped to $0,7 \mathrm{~V}$ and the potential of the Paracetamol/graphite-electrode under stress increased from $+0,28 \mathrm{~V}$ to $+0,37 \mathrm{~V}$. After 60 minutes operating time the electric motor was removed from the circuit. The voltage of the battery (without electrical load) increased to $1,15 \mathrm{~V}$ and the potential of the Paracetamol/graphite-electrode dropped to $+0,05 \mathrm{~V}$ within a short period of time. Figure 10 shows the progress of the measured data. Oxygen is being reduced at the cathode (Figure 7) whereas Paracetamol is being oxidized to $\mathrm{N}$ acetyl-p-benzoquinone imine (Figure 11) at the anode. 


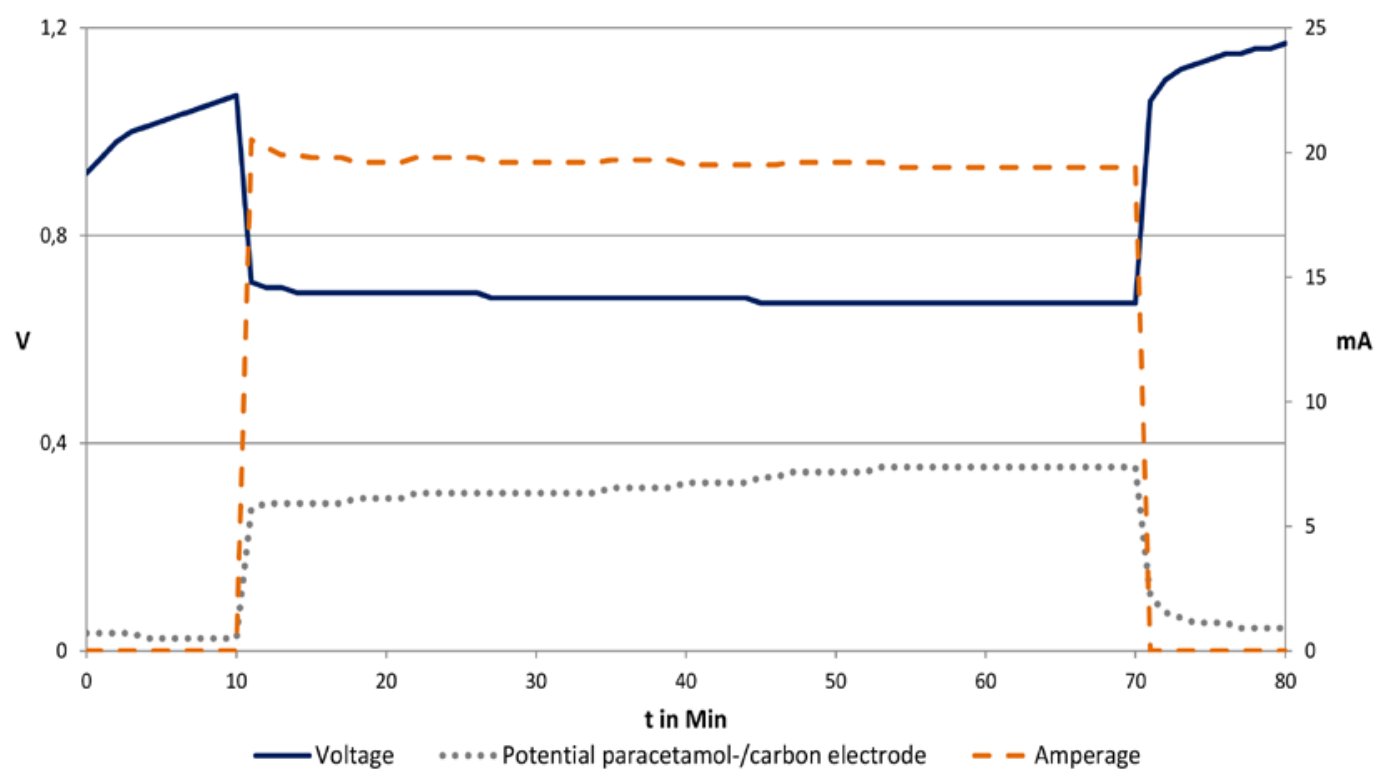

Figure 10. Measured voltage, current and potential of the Paracetamol-Oxygen-Battery<smiles>CC(=O)Nc1ccc([O-])cc1</smiles>

Figure 11. Oxidation of Paracetamol

Beside oxygen one can use iron(III)-sulfate and p-Benzoquinone as described before in the experiments with p-Phenylenediamine. The procedure was done as described in experiments 2 and 3. The operating battery yielded good results. Because of the fact, that Paracetamol is a derivative of p-Aminophenol, it is clear to test this substance as well as a material for organic flow batteries.

\subsubsection{Experiment 4:}

\section{p-Aminophenol/iron(III)-sulfate-battery}

Used Equipment: See experiment 3

Chemicals: See experiment 2. Instead of p-Phenylenediamine
p-Aminophenol is used (10 $\mathrm{g}$ in $200 \mathrm{~mL}$ sodium hydroxide solution with a concentration of $\mathrm{c}(\mathrm{NaOH})=$ $1 \mathrm{~mol} / \mathrm{L}$ )

Procedure: The prepated p-Aminophenol solution is used. The procedure is done just as in experiment 2. A powerful electric motor is used.

Results and interpretation: The Ruheklemmenspannung was at $0,88 \mathrm{~V}$ and the resting potential of the p-Aminophenol /graphite electrode was found to be $-0,14 \mathrm{~V}$. After turning on the electric motor it consumed a current of $15 \mathrm{~mA}$ and the voltage dropped to $0,66 \mathrm{~V}$ and later to $0,64 \mathrm{~V}$. The potential increased to $-0,04 \mathrm{~V}$ and later on to $-0,02 \mathrm{~V}$. The Ruheklemmspannung turned out to be $0,88 \mathrm{~V}$ and the resting potential of the p-Aminophenol /graphite electrode after an operating time of 30 minutes. All findings can be found in Figure 12. The reaction equation of the anode can be seen in Figure 13 and the cathode in Figure 7.

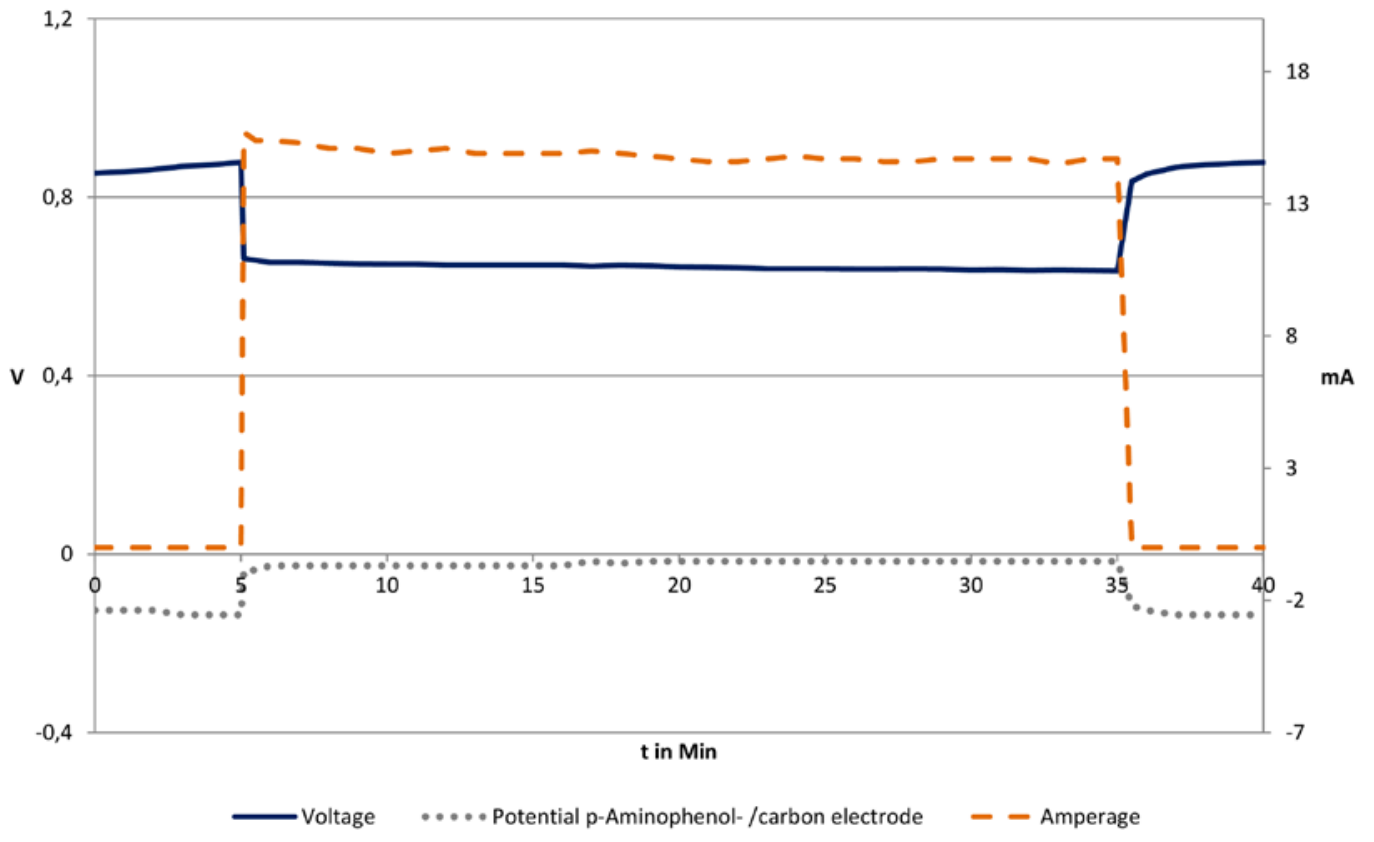

Figure 12. Measured voltage, current and potential of the $\rho$-Aminophenol-iron(III)sulfate-battery 
<smiles>N=C1C=CC(=O)C=C1</smiles>

Figure 13. Oxidation of p-Aminophenol

$\rho$-Aminophenol solution is still used today as a developer solution in photography. These solutions, which contain about $5 \mathrm{~g} \rho$-Aminophenol in $100 \mathrm{~mL}$ can be purchased via special shops (www.photo-lang.de, Rollei R09 ONE SHOT, Negativentwickler, 14,90 €). These solutions are alkaline and the concentration of the used potassium hydroxide is about $\mathrm{c}(\mathrm{KOH})=0,9 \mathrm{~mol} / \mathrm{L}$. These solutions are usable in experiments done by students according to the criteria given by the DGUV [18].

\subsubsection{Experiment 5: Battery Using Developer Solution with the Carbon/Oxygen Electrode}

Used Equipment and chemicals: See experiment 1. Additionally a developer for photography is used (source: www.photo-lang.de, Rollei R09 ONE SHOT)

Procedure: The beaker glass is filled with $150 \mathrm{ml}$ developer solution. It can be used as purchased without using further sodium hydroxide solution. The rest of the procedure is done as in experiment 1.

Results and interpretation: The resting potential of the developer solution / graphite electrode was measured at $-0,12 \mathrm{~V}$ and the resting potential of oxygen electrode according to Oetken at $0,20 \mathrm{~V}$. The Ruheklemmspannung is $1,31 \mathrm{~V}$. The weak electric motor with a current consumption of $2,3 \mathrm{~mA}$ as well as the powerful electric motor with a current consumption of $20 \mathrm{~mA}$ could be operated over a long period of time. Even two powerful electric motors could be used with this battery. The experimental data are depicted in Figure 14. The reaction equation of the anode is seen in Figure 13 and the cathodic reaction equation is given in Figure 7.

By analogy to the experiments done with Paracetamol battery in the p-Aminophenol battery iron(III)-sulfate and $\rho$-Benzoquinone can be used. The procedure is then analog to experiment 2 and 3. With the p-Aminophenol / $\rho$-Benzoquinone battery even a powerful electric motor can be used.

\subsubsection{Reversibility of the Oxidation Reaction of Paracetamol und p-Aminophenol}

In order to check the rechargabilty of the Paracetamol and the p-Aminophenol battery, respectively, both substances were tested via cyclic voltammetry. The results presented of p-Aminophenol in a basic medium exhibit almost perfect reversibility of the oxidation (cf. Figure 15 a). This leads to the conclusion that a system consisting of a pAminophenol cell in an alkaline medium combined with a p-benzoquinone cell in an acidic medium represents an almost perfect electrochemical system, because of its almost perfect rechargeability.

Paracetamol on the other hand shows an irreversible oxidation: there is now reduction peak present. The reduction of the $\mathrm{N}$-acetyl-p-benzoquinone imine formed due to the oxidation of Paracetamol is inhibited. It is nevertheless an interesting system: if left untouched for a period of three and six days, respectively, one can clearly observe the peaks of p-Aminophenol, whereas the peak of the oxidation of Paracetamol diminishes (Figure $15 \mathrm{~b}-\mathrm{d}$ ). This demonstrates that a removal of the acetylgroup is taking place in alkaline medium (Figure 16).

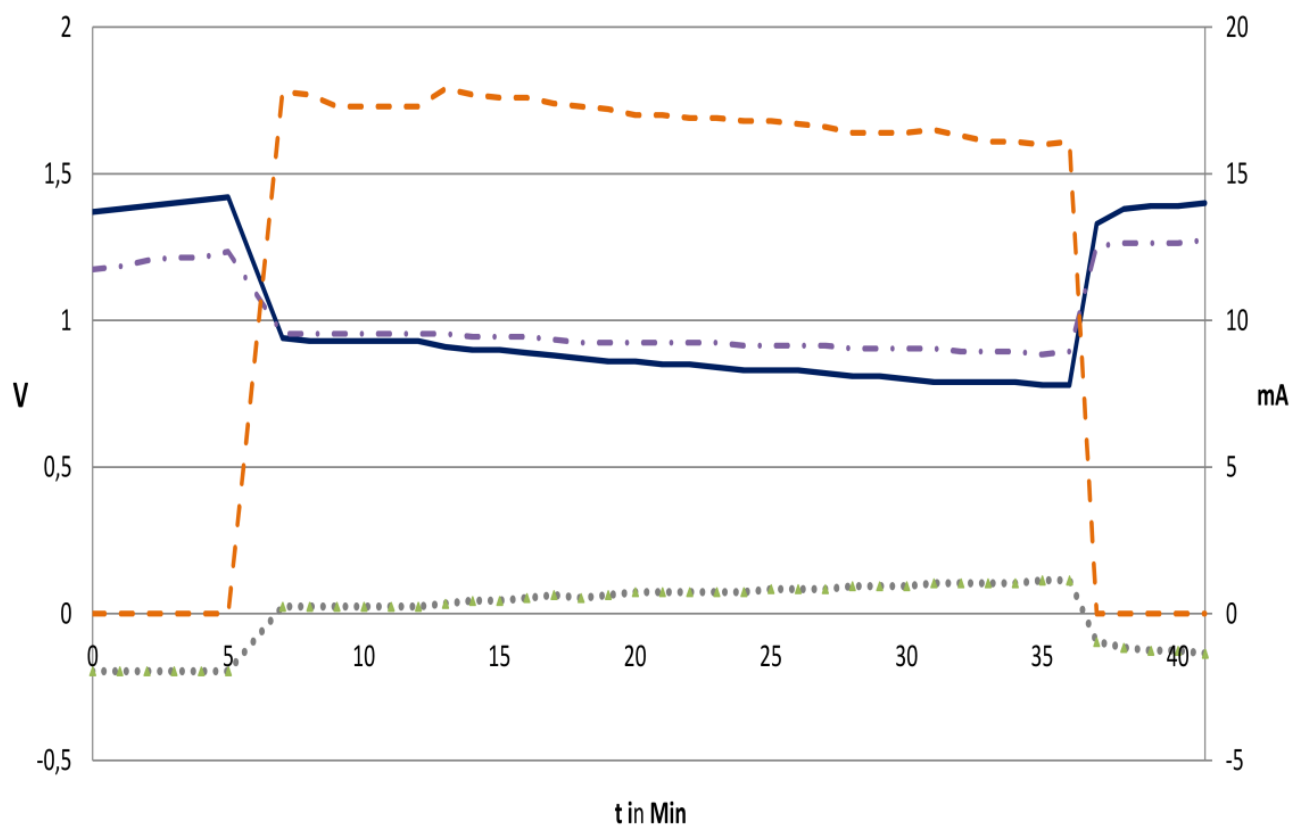

- Voltage $\quad \ldots . .$. Potential Photo developer-/ carbon electrode - . Potential ODC - - Amperage

Figure 14. Measured voltage, current and potential of the developer-oxygen-battery 

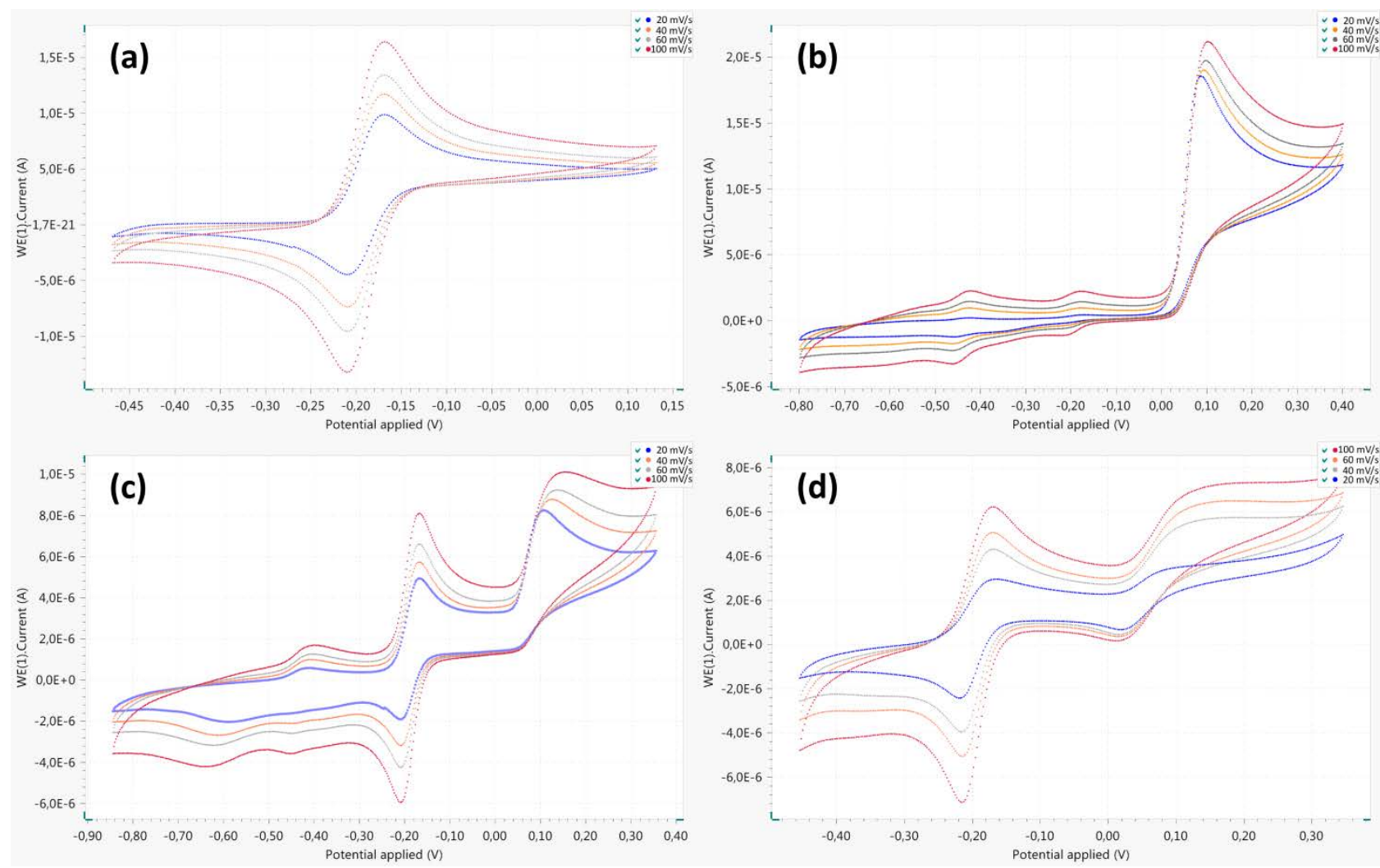

Figure 15. Cyclic voltammograms of p-Aminophenol (a), Paracetamol (freshly prepared) (b), Paracetamol (after 3 days) (c) and Paracetamol after 6 days (d) all measured against an $\mathrm{Ag} / \mathrm{AgCl}$ electrode<smiles>CC(=O)Nc1ccc([O-])cc1N</smiles>

Figure 16. Removal of the Acetylgroup in Paracetamol

\subsection{Outlook}

With p-Benzquinone in acidic solution and p-Aminophenol in alkaline solution, we presented systems which prove to be suitable candidates for organic Redox-Flow-Batteries, because of their reversible behavior concerning oxidation and reduction reaction. To find systems which exhibit rechargeability with lower potentials on the anodic and higher potentials on the cathodic side would be desirable. We will report on these findings in the near future.

\section{Acknowledgements}

We thank the "Fonds der chemischen Industrie" for funding this research project.

\section{References}

[1] Sterner, M., Stadler, I., Energiespeicherung - Bedarf, Technologien, Integration, Berlin-Heidelberg, 2014, 282-290.

[2] Kurzweil, P., Dietlmeier, O. K., Elektrochemische Speicher Superkondensatoren, Batterien, Elektrolyse-Wasserstoff, Rechtliche Grundlagen, Wiesbaden, 2015, 343-346.
[3] Huskinson, B., Nawar, S., Gerhardt, M. R., Aziz, M., "Novel Quinone-Based Couples for Flow-Batteries.”, ECS Transactions, 57 (7). 101-105. 2013.

[4] Huskinson, B., Marshak, M.P., Changwon, S., Süleyman, E., Gerhardt, M. R., Galvin, C. J., Chen, X., Aspuru-Guzik, A., Gordon, R. G., Aziz, M., "A metal-free organic - inorganic aqueous flow-battery.”, Nature, 505. 195-198. 2014.

[5] Yang, B., Hoober-Burkhardt, L., Wang, F., Prakash, G. K. S., Narayanan, S. R., "An Inexpensive Aqueous Flow Battery for Large-Scale Electrical Energy Storage Based on Water-Soluble Organic Redox Couples.”, ESC, 161(p). 1371-A1380. 2014.

[6] Rosenberg, D., Behnisch, M., Pansegrau, S., Busker, M., Jansen, W., "Speicherung elektrischer Energie mit neuartigen, organischen Batterien", Praxis der Naturwissenschaften-Chemie in der Schule, 65 (4). 36-42. 2016.

[7] Rosenberg, D., Wachholz, M., Busker, M., Jansen, W., "Organische Batterien mit Alizarin.“, Praxis der Naturwissenschaften-Chemie in der Schule, 65 (3). 14-19. 2016.

[8] Rosenberg, D., Rehling, A., Busker, M., Jansen, W., “Organische Batterien mit Gallussäure, Pyrogallol und grünem Tee. Schulexperimente zur Demonstration von Flow-Batteries.“, Praxis der Naturwissenschaften-Chemie in der Schule, 65 (6). 22-27. 2016.

[9] Rosenberg, D., Rehling, A., Ernst, D., Busker, M., Jansen, W., "Organische Batterien mit Phloroglucin und Vanillin.“, Praxis der Naturwissenschaften-Chemie in der Schule, 66 (2). 9-14. 2017.

[10] Hamann, C. H., Vielstich, W., Elektrochemie, Wiley-VCH-Verlag, Weinheim, 1998.

[11] Heinze, J., "Cyclic Voltammetry - Electrochemical Spectroscopy", Angewandte Chemie, 23 (11). 831-918. 1984.

[12] Habekost, A., "Die Elektrochromie von Tetramethylphenylendiamin, Diphenylamin und Methylviologen im Vergleich“, Praxis der Naturwissenschaften-Chemie in der Schule, 64 (8). 13-18. 2015.

[13] Habekost, A., "Experimental Investigations of Alkaline Silverzinc and Copper-zinc Batteries", World Journal of Chemical Education, 1 (4). 4-12. 2016.

[14] Klaus, M., Hasselmann, M., Rubner, I., Mößner, B., Oetken, M., "Metall-Luft-Batterien mit einer neuartigen Kohleelektrode", Chemkon, 21 (2). 65-71. 2014. 
[15] Dierks, W., Vennemann, H., "Mit Peroxodisulfat zu extremen Potentialdifferenzen - eine 5V-Monozelle“, Chemkon, 11 (4). 197-198. 2004

[16] Wegner, C., Pulka, S., Risch, B., "Synthese und Analyse des Arzneistoffs Paracetamol im Schülerlabor", Chemkon, 23 (3). 131140. 2016.
[17] Brune, K., "150 Jahre Analgetika. Paracetamol: gefährlicher als man denkt", Chemie in unserer Zeit, 49. 402-409. 2015.

[18] Deutsche Gesetzliche Unfallversicherung (DGUV), Stoffliste zur Regel, Unterricht in Schulen mit gefährlichen Stoffen', GDUV Regel 113-019, Berlin, 2010. 